\title{
PENGARUH ISLAM TERHADAP PERKEMBANGAN BUDAYA JAWA: Tembang Macapat
}

\author{
Asmaun Saflan dan Mulyono \\ Fakultas Tarbiyah UIN Maulana Malik Ibrahim Malang \\ Telp.081252866886, email: asmaun-tarbiyah@yahoo.com
}

\section{Abstracs}

Islam came to Indonesia since the seventh century $\mathrm{AD}$ has a major influence on the transformation of the local culture. From cultures that were previously heavily influenced by Hinduism is primarily based on two major books from India, the Ramayana and the Mahabharata to the new culture that is influenced by Islamic values. One form of cultural transformation in the field of Javanese literature is the birth of the tembang macapat (song of macapat). Tembang macapat is a form of transformation from Javanese literature of the form kakawin literary dan kidung (ancient Javanese song) became a form of Java new song (gending). During its development, macapat song contains a lot of Islamic values so utilized by teachers, preachers, religious scholars and Ulama' to the means of education and transformation of Islamic values.

Islam datang ke Indonesia sejak abad ke tujuh Masehi memiliki pengaruh besar terhadap transformasi budaya setempat. Dari kebudayaan yang sebelumnya banyak dipengaruhi oleh agama Hindu terutama didasarkan pada dua karya besar dari India yaitu Ramayana dan Mahabharata menuju kepada kebudayaan baru yang dipengaruhi oleh nilai-nilai Islam. Salah satu bentuk transformasi kebudayaan dalam bidang sastra Jawa adalah lahirnya tembang macapat. Tembang macapat merupakan bentuk transformasi sastra Jawa dari bentuk kakawin dan kidung menjadi sastra puisi yang berupa lagu/gending. Dalam perkembangannya, tembang macapat banyak mengandung nilai-nilai Islam sehingga dimanfaatkan oleh para guru, mubaligh, kyai maupun ulama' untuk sarana pendidikan dan dakwah nilai-nilai Islam.

Key words: Islam, Java culture, tembang macapat 


\section{Pendahuluan}

Kebudayaan Jawa tumbuh dan berkembang sejak terbentuknya masyarakat Jawa. Dari hasil penelitian prasejarah dapat diketahui bahwa masyarakat Jawa pada zaman batu baru telah mengenal kebudayaan yang tinggi. Dari benda-benda prasejarah yang diketemukan terbukti bahwa masyarakat Jawa telah mengembangkan budaya bercocok tanam dengan sistem irigasi. Organisasi sosial masyarakat di zaman itu juga sudah teratur. Pada zaman batu besar masyarakat Jawa juga telah mengenal sistem religi berupa pemujaan arwah leluhur. Terbukti dari banyaknya punden berundak-undak dan peninggalan dolmen, kubur batu dan menhir yang diketemukan. Penemuan batu menhir membuktikan telah dikenalnya upacara kesuburan yaitu memancangkan di tanah sebagai lambang kesatuan pria dan wanita. Upacara tersebut secara magis dianggapnya dapat menyebabkan kesuburan tanah dan menghasilkan tanaman untuk memenuhi kebutuhan hidup manusia (Heekeren, 1957: 23).

Manusia Jawa pada zaman prasejarah telah mengenal sepuluh unsur kebudayaan sebelum ada persebaran pengaruh kebudayaan luar ke Jawa. Kesepuluh unsur itu adalah: pertanian beririgasi, batik, pelayaran, metrum, perbintangan, pengecoran logam, wayang, mata uang, gamelan, dan sistem pemerintahan yang teratur (Brandes, 1889: 51).

Dalam perkembangannya pada jaman kolonial Belanda, raja-raja Jawa kehilangan kekuasaan politiknya. Untuk mempertahankan kewibawaan raja maka dipusatkan perhatian di bidang seni budaya. Para pujangga dan empu kraton ditugaskan untuk menciptakan karya seni yang seindah-indahnya. Ternyata sikap tersebut memang dapat berhasil menjaga kewibawaan dan keagungan kerajaan serta kraton menjadi pusat kebudayaan Jawa. Bagi para pujangga, karya seni bukan saja sebagai tujuan berkarya tetapi lebih dalam maknanya ialah bahwa selama berkarya itu tak ubahnya sebagai sikap yoga samadi untuk mendekatkan jiwanya dengan Sang Maha Pencipta. Dengan sikap jiwa seperti itu karya seni yang dihasilkan bukan saja indah bagi pengamatan indera tetapi juga mencerahkan jiwa bagi yang menikmatinya (Wibisono, 2009:1).

Karya para pujangga dan para empu itu meliputi seni sastra, seni tari, seni karawitan, seni drama, seni karya dan lain-lain yang kemudian dikenal sebagai seni klasik. Masa itupun dapat disebut sebagai masa renaissance budaya Jawa. Di bidang seni sastra masa itu disebut sebagai “jaman kapujanggan” Local genious budaya Jawa itu terus tumbuh dan berkembang serta diungkapkan dalam orientasi, persepsi, sikap dan cara hidup yang sesuai dan mampu mendukung proses modernisasi, salah satunya diungkapkan melalui tembang 
macapat (Wibisono, 2009:2).

Tembang macapat merupakan bagian penting dari budaya Nusantara utamanya Jawa. Bahkan tembang macapat dengan segala kandungan isinya memiliki berbagai fungsi sebagai pembawa amanat, sarana penuturan, penyampaian ungkapan rasa, media penggambaran suasana, penghantar teka-teki, media dakwah, alat pendidikan serta penyuluhan, dan sebagainya (Purna, 1996: 3). Semuanya dapat terwadahi oleh tembang macapat, baik halhal yang terlihat nyata dalam bentuk tersurat, maupun kandungan-kandungan yang tersimpan (tersirat). Uraian singkat ini menunjukkan betapa tinggi nilai yang terkandung di dalam tembang macapat beserta amanat yang tersurat dan tersirat dalam rangka upaya memperluas cakrawala budaya sebagai landasan pengembangan kebudayaan Indonesia masa kini maupun mendatang.

Mengamati sastra lama khususnya tembang macapat dalam rangka menggali kebudayaan Indonesia merupakan usaha yang erat hubungannya dengan pembangunan bangsa Indonesia seutuhnya. Pembangunan negara yang sifatnya multikompleks memberi tempat kepada bidang mental spiritual. Berbicara mengenai sastra adalah identik berbicara tentang kehidupan. Kita boleh bangga bahwasanya bangsa Indonesia memiliki dokumen-dokumen sastra lama, diantaranya dalam bentuk tembang macapat sebagai salah satu warisan nenek moyang. Namun demikian kita tidak boleh puas dengan cukup berbangga hati saja terhadap peninggalan yang ada. Di samping menjaga kelestariannya, kita seyogyanya juga dapat berbuat sesuatu terhadap peninggalan-peninggalan tersebut sebagai langkah apresiatif atas kreativitas para cerdik cendikiawan dari masa lampau itu dalam memberi makna lagi dalam kehidupan di abad global ini. Termasuk bagian dari langkah apresiatif tersebut dalam artikel ini penulis mengkaji satu tema dengan rumusan masalah: bagaimana pengaruh Islam dalam perkembangan budaya Jawa tembang macapat?. Tujuan dari kajian ini adalah untuk menjelaskan secara gamblang pengaruh Islam terhadap perkembangan budaya Jawa tembang macapat.

\section{Metode Penelitian}

Untuk menjawab rumusan masalah yang diajukan dalam penelitian ini, maka jenis penelitian yang dipergunakan adalah penelitian kepustakaan (library research). Dengan library research, sebuah penelitian dapat menggunakan metode deskriptif analitik, yaitu data yang diperoleh berupa kata-kata, gambar dan perilaku yang tidak dituangkan dalam bentuk bilangan atau statistik, melainkan tetap dalam bentuk kualitatif dengan memberi pemaparan gambaran mengenai 
situasi yang diteliti dalam bentuk uraian naratif (Margono, 2000: 39). Untuk mempertajam analisis metode deskriptif kualitatif, peneliti menggunakan teknik analisis isi (content analisys), yaitu suatu analisis yang menekankan pada analisis ilmiah tentang isi pesan suatu komunikasi (Moleong, 1990:163-164). Content analisys memanfaatkan prosedur yang dapat menarik kesimpulan shahih dari sebuah buku atau dokumen (Muhadjir, 1992: 72). Proses content analisys adalah dimulai dari isi pesan komunikasi tersebut, dipilah-pilah (disortir), kemudian dilakukan kategorisasi (pengelompokan) antara data yang sejenis, dan selanjutnya dianalisis secara kritis dan obyektif (Bleicher, 1980: 28).

Jenis data yang diperlukan dalam penelitian ini adalah data kualitatif yang sifatnya tekstual. Sumber data dipilih menjadi tiga, yaitu: sumber data primer, sekunder dan penunjang. Adapun data primer penelitian ini adalah data kepustakaan yang membahas tentang tembang macapat, antara lain: Mulyono (2007), Kajian Nilai Pendidikan Islam dalam Teks Tembang Macapat (Studi Nilai Pendidikan Islam Berbasis Kultural); Budya Pradipta (1994), Kehidupan Macapat di Propinsi Jawa Tengah; I Made Purna, dkk. (1996), Macapat dan Gotong Royong; dan Amir Rochyatmo (tt.) Tembang Macapat yang Tersurat dan Tersirat. Adapun dokumen sekunder dan penunjang yaitu sejumlah dokumen kepustakaan lainnya maupun hasil download di internet yang mendukung terhadap kajian pengaruh Islam terhadap perkembangan budaya Jawa tembang macapat.

\section{Istilah Tembang Macapat}

Kata tembang sebagai "nyanyian" bersinonim dengan kidung, kakawin, dan gita. Kata kakawin berasal dari kawi (bahasa Sansekerta) yang berarti "penyair". Kakawin berarti "syair, gubahan, kidung, nyanyian" (Mardiwarsito, 1981:274). Kata kidung berarti "nyanyian", sudah dikenal sejak terciptanya karya sastra Jawa Kuno. Sedangkan kata tembang baru dijumpai dalam karya sastra Jawa Baru. Kemudian kata kakawin, kidung, dan tembang digunakan sebagai sebutan bentuk puisi Jawa secara kronologis. Kakawin merupakan sebutan puisi Jawa Kuno berdasarkan metrum India. Kidung sebagai sebutan puisi Jawa pertengahan berdasarkan metrum Jawa, dan tembang adalah sebutan puisi Jawa baru berdasarkan metrum Jawa.

Berkaitan dengan kata tembang, muncul kata macapat yang kemudian digabung menjadi "tembang macapat". Kata macapat diperkirakan bukan berasal dari bahasa Jawa Kuno atau Kawi dan bukan berasal dari bahasa Jawa Pertengahan atau Jawa Madya, melainkan dari bahasa Jawa Baru (Danusuprapta, 1981:151). Bahasa Jawa Baru adalah bahasa yang digunakan dalam karya 
sastra Jawa pada akhir abad ke-16 Masehi setelah ada pengaruh Islam terhadap budaya Nusantara khususnya Jawa.

Tembang macapat merupakan tembang yang konon berasal dari kata "mocone papat papat" (membacanya empat empat). Menurut Poerwardarminta, macapat adalah tembang yang biasa digunakan atau terdapat dalam kitab-kitab Jawa Baru. Karseno Saputra mendefinisikan: macapat adalah karya sastra berbahasa Jawa Baru berbentuk puisi yang disusun menurut kaidah-kaidah tertentu meliputi guru gatra, guru lagu, dan guru wilangan (Saputra, 1992:8). Menurut Budya Pradita macapat adalah puisi tradisi Jawa yang ditembangkan secara vocal, tanpa iringan instrumen apapun dengan patokan-patokan tertentu, meliputi patokan tembang dan patokan sastra (Purna, 1996:3).

Dengan demikian dapat diberi pengertian bahwa yang disebut tembang macapat adalah bentuk tembang yang merupakan bentuk puisi Jawa tradisional yang menggunakan bahasa Jawa Baru dengan memiliki aturan-aturan atau patokan-patokan sastra Jawa. Atau dengan kata lain tembang macapat adalah karya sastra berbahasa Jawa Baru berbentuk puisi yang cara mengungkapannya diwujudkan dalam bentuk tembang/lagu serta disusun dengan menurut kaidah-kaidah tertentu, meliputi guru gatra, guru lagu, dan guru wilangan.

\section{Pengaruh Islam dalam Perkembangan Tembang Macapat}

Macapat sebagai sebutan metrum puisi Jawa Pertengahan dan Jawa Baru, yang hingga kini masih digemari masyarakat, ternyata sulit dilacak sejarah penciptaannya. Purbatjaraka menyatakan bahwa macapat lahir bersamaan dengan syair berbahasa Jawa Tengahan; bilamana macapat mulai dikenal, belum diketahui secara pasti. Pigeud berpendapat bahwa tembang macapat digunakan pada awal periode Islam. Pernyataan Pigeud yang bersifat informasi perkiraan itu masih perlu diupayakan kecocokan tahunnya yang pasti (Saputra, 1992:14).

Karseno Saputra memperkirakan atas dasar analisis terhadap beberapa pendapat dan pernyataan. Apabila pola metrum yang digunakan pada tembang macapat sama dengan pola metrum tembang tengahan dan tembang macapat tumbuh berkembang sejalan dengan tembang tengahan, maka diperkirakan tembang macapat telah hadir di kalangan masyarakat peminat setidak-tidaknya pada tahun 1541 masehi. Perkiraan itu atas dasar angka tahun yang terdapat pada Kidung Subrata, Juga Rasa Dadi Jalma yang bertahun 1643 Jawa atau 1541 Masehi (Saputra, 1992:14).

Penentuan ini berpangkal pijak dari pola metrum macapat yang paling 
awal yang terdapat pada Kidung Subrata. Sekitar tahun itu hidup berkembang puisi berbahasa Jawa Kuno, Jawa Tengahan, dan Jawa Baru, yaitu kakawin, kidung, dan macapat. Tahun perkiraan itu sesuai pula dengan pendapat Zoetmulder bahwa lebih kurang pada abad XVI di Jawa hidup bersama tiga bahasa, yaitu Jawa Kuno, Jawa Tengahan, dan Jawa Baru.

Dalam Mbombong Manah I (Sumarto, 1958:5) disebutkan bahwa tembang macapat (yang mencakup 11 metrum) diciptakan oleh Prabu Dewawasesa atau Prabu Banjaran Sari dari Sigaluh pada tahun 1191 Jawa (1279 Masehi). Tetapi menurut sumber lain, tampaknya macapat tidak hanya diciptakan oleh satu orang, tetapi oleh beberapa orang wali dan bangsawan (Laginem, 1996: 27). Para pencipta itu adalah Sunan Giri Kedaton, Sunan Giri Prapen, Sunan Bonang, Sunan Gunung Jati, Sunan Muryapada, Sunan Kali Jaga, Sunan Drajat, Sunan Kudus, Sunan Geseng, Sunan Majagung, Sultan Pajang, Sultan Adi Eru Cakra, dan Adipati Nata Praja.

Namun berdasarkan kajian ilmiah, ada dua pendapat yang memiliki sedikit perbedaan tentang timbulnya macapat. Pendapat pertama bertumpu bahwa tembang macapat lebih tua dibanding tembang gede dan pendapat kedua bertumpu pada anggapan sebaliknya. Kecuali pendapat itu ada pendapat lain tentang timbulnya macapat berdasarkan perkembangan bahasa.

a. Tembang macapat lebih tua daripada tembang gede

Pendapat pertama beranggapan bahwa tembang macapat lebih tua daripada tembang gede tanpa wretta atau tembang gede kawi miring. Tembang macapat timbul pada zaman Majapahit akhir, ketika pengaruh kebudayaan Hindu mulai surut (Danusuprapta, 1981:153-154). Dikemukakan pula oleh Purbatjaraka bahwa timbulnya macapat bersamaan dengan kidung, dengan anggapan bahwa tembang tengahan tidak ada (Poerbatjaraka, 1952:72).

b. Tembang macapat lebih muda daripada tembang gede

Pendapat kedua beranggapan bahwa tembang macapat timbul pada waktu pengaruh kebudayaan Hindu semakin menipis dan rasa kebangsaan mulai tumbuh, yaitu pada zaman Majapahit akhir. Lahirnya macapat berurutan dengan kidung, muncullah tembang gede berbahasa Jawa Pertengahan, berikutnya muncul macapat berbahasa Jawa Baru.

Pada zaman Surakarta awal timbul tembang gede kawi miring. Bentuk gubahan berbahasa Jawa Baru banyak digemari adalah kidung dan macapat. Proses pemunculannya bermula dari lahirnya karya-karya berbahasa Jawa Pertengahan yang biasa disebut dengan kitab Kidung, kemudian muncul karya-karya berbahasa Jawa Baru berupa kitab Suluk dan kitab Niti yang sudah kental dengan pengaruh nilai-nilai Islam. Kitab suluk dan niti itu 
memberikan sumbangan yang besar terhadap perkembangan macapat.

c. Tembang macapat berdasarkan perkembangan bahasa

Secara linguistik bahasa Jawa Pertengahan bukan merupakan pangkal bahasa Jawa Baru, melainkan merupakan dua cabang yang terpisah dan divergen pada bahasa Jawa Kuno. Bahasa Jawa kuno merupakan bahasa umum selama periode Hindu-Jawa sampai runtuhnya Majapahit (Zoetmulder, 1983: 35).

Sejak datang pengaruh Islam, bahasa Jawa Kuno berkembang menurut dua arah yang berlainan yang menimbulkan bahasa Jawa Pertengahan dan bahasa Jawa Baru. Kemudian, bahasa Jawa Pertengahan dengan kidungnya berkembang di Bali dan bahasa Jawa Baru dengan macapatnya berkembang di Jawa. Bahkan, sampai sekarang tradisi penulisan karya sastra Jawa Kuno dan Pertengahan masih ada di Bali. Berdasarkan beberapa pendapat tentang perkembangan sastra Jawa dan pengaruh Islam terhadap bentuk dan isi tembang macapat maka penulis dapat simpulkan dalam bagan. Lihat Gambar 1.

Dari beberapa pendapat dan alur bagan di atas kalau kita kaitkan dengan keberadaan kerajaan, maka pada sekitar abad XVI tersebut sedang berkuasa kerajaan Islam Demak Bintoro, Pajang dan Mataram Islam dengan didukung oleh pengaruh para Wali Songo. Maka dari itu berdasarkan beberapa pendapat yang mengatakan bahwa macapat lahir pada zaman Islam yaitu zaman Demak Bintoro kemungkinan besar ada benarnya, walaupun boleh jadi bentuk sajaknya (metrum) sedikit banyak tetap dipengaruhi oleh model kakawin dan kidung yang sudah tumbuh pada zaman sebelumnya, yaitu sejak zaman Kediri antara abad 10-12 masehi dan zaman kejayaan Majapahit antara abad 13-15 masehi. Dengan demikian dapat disimpulkan bahwa ada kemungkinan besar tembang macapat lahir dan berkembang pada zaman kerajaan Islam dan para wali songo sebagai pengubahnya walaupun tetap dipengaruhi oleh model metrum sastra yang telah berkembang sebelumnya yaitu model kakawin dan kidung.

\section{Perwatakan Tembang Macapat}

Dalam tembang macapat terdapat watak yang erat kaitannya dengan isi metrum dan lagu. Dalam teks yang bermetrum Asmarandana, misalnya, watak yang dimiliki adalah rasa sedih, rindu, dan mesra sehingga isinya terkandung didalamnya melukiskan rasa sedih, rindu, dan mesra pula. Apabila teks itu didendangkan, lagunya harus sesuai dengan suasana yang terdapat dalam isinya. Dengan demikian, penggunaan suatu metrum harus sesuai dengan wataknya karena watak turut menentukan nilai keindahan tembang. Setiap tembang 
mempunyai watak yang berbeda dari jenis tembang yang lain. Watak tembang telah dirumuskan dalam beberapa aturan baku kesusasteraan Jawa. Di bawah ini dijelaskan perwatakan tembang macapat, sebagai berikut :

1) Asmaradana; berwatak: sedih, rindu, mesra. Kegunaan: menyatakan rasa sedih, rindu, mesra.

2) Balabak; berwatak: santai, seenaknya. Kegunaan: menggambarkan suasana santai, kurang sungguh-sungguh.

3) Durma; berwatak: bersemangat, keras, galak. Kegunaan: mengungkapkan kemarahan, kejengkelan, peperangan.

4) Dandanggula; berwatak: manis, luwes, memukau. Kegunaan: menggambarkan berbagai hal dan suasana.

5) Gambuh; berwatak: wajar, jelas, tanpa ragu-ragu. Kegunaan: mengungkapkan hal-hal bersifat kekeluargaan, nasihat, dan kesungguhan hati.

6) Girisa; berwatak: hati-hati, sungguh-sungguh. Kegunaan: melukiskan hal-hal yang mengandung kewibawaan, pendidikan, pengajaran.

7) Jurudemung; berwatak: senang, gembira, menggoda. Kegunaan: melukiskan hal-hal yang mengandung banyak tingkah, memancing asmara.

8) Kinanti; berwatak: terpadu, gembira, mesra. Kegunaan: memberi nasihat, mengungkapkan kasih sayang.

9) Maskumambang; berwatak: susah, sedih,terharu, merana, penuh derita. Kegunaan: melukiskan suasana sedih, pilu, penuh derita.

10) Megatruh; berwatak: susah, sedih, penuh derita, kecewa, menerawang. Kegunaan: melukiskan suasana sedih pilu, penuh derita, menerawang.

11) Mijil; berwatak: terharu, terpesona. Kegunaan: menyatakan suasana haru, terpesona dalam hubungannya dengan kasih sayang, nasihat.

12) Pangkur; berwatak: gagah, perwira, bergairah, bersemangat. Kegunaan: memberikan nasihat yang bersemangat, melukiskan cinta yang berapiapi, suasana yang bernada keras.

13) Pucung; berwatak: santai, seenaknya. Kegunaan: menggambarkan suasana santai, kurang bersungguh-sungguh.

14) Sinom; berwatak: senang, gembira, memikat. Kegunaan: menggambarkan suasana, gerak yang lincah.

15) Wirangrong: berwatak: berwibawa. Kegunaan: mengungkapkan suasana yang mengandung keagungan, keindahan alam, pendidikan. (Tim Wacana Nusantara, 2009). 


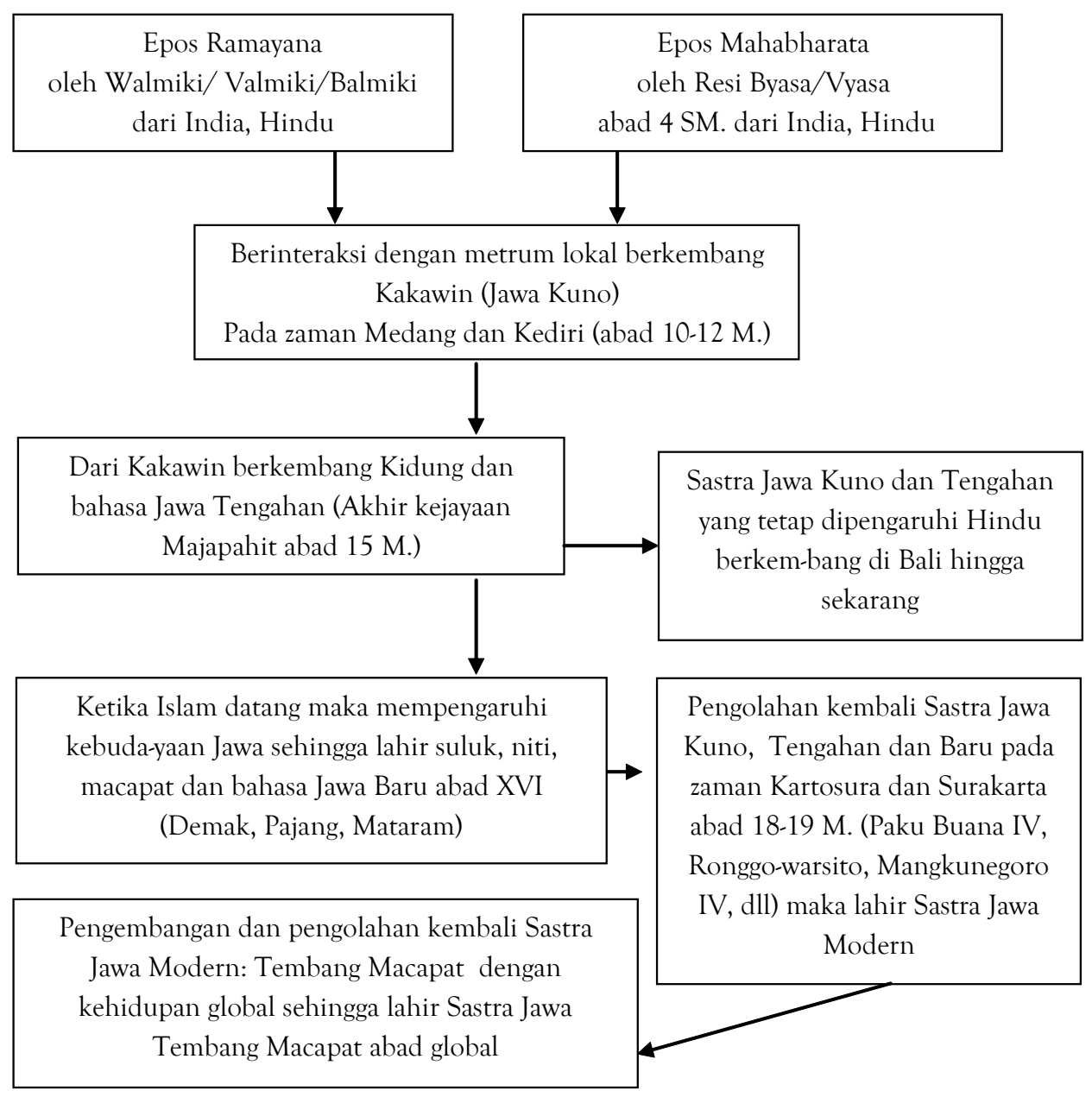

Gambar 1. Alur Perkembangan Sastra Jawa serta pengaruh Islam terhadap Tembang Macapat (Sumber: Mulyono, 2009)

Tembang macapat disebut tembang cilik. Selain tembang cilik ada juga tembang tengahan dan tembang gedhe. Yudayana mengelompokkan tiga jenis tembang atas tembang macapat atau tembang alit, tembang tengahan dan tembang gedhe. Tembang macapat paling dikenal, banyak digemari dan mudah dipelajari (Darnavi, 1984: 132). Ranggawarsita menyatakan bahwa macapat adalah tembang cilik. Tembang lainnya adalah tembang tengahan dan tembang gedhe. Ia mengelompokkan tembang macapat sebanyak delapan buah. Jumlah itu termasuk tembang macapat murni. Hardjawiraga menggabungkan 15 tembang ke dalam kelompok tembang macapat dengan melibatkan tembang 
tengahan. Lima belas tembang itu adalah:
1) Dhandanggula
: 10i, 10a, 8e, 7u, 9i, 7a, 6u, 8a, 12i, 7a
2) Sinom
: 8a, 8i, 8a, 7i, 8u, 7a, 8i, 12a
3) Kinanthi
: 8u, 8i, 8a, 8i, 8a, 8i
4) Pangkur
: 8a, 11i, 8u, 7a, 12u, 5a, 8i
5) Asmaradana
: 8i, 8a, 8e/8o, 8a, 7a, 8u, 8a
6) Mijil
: 10i, 6o, 10e, 10i, 6i, 6u
7) Gambuh
: $7 \mathrm{u}, 10 \mathrm{u}, 12 \mathrm{i}, 8 \mathrm{u}, 8 \mathrm{o}$
8) Pocung
: $12 \mathrm{u}, 6 \mathrm{a}, 8 \mathrm{i}, 8 \mathrm{a}$
9) Durma
: 12a, 7i, 6a, 7a, 8i, 5a, 7i
10) Megatruh
: $12 \mathrm{u}, 8 \mathrm{i}, 8 \mathrm{u}, 8 \mathrm{i}, 8 \mathrm{o}$
11) Maskumambang
$: 12 \mathrm{u}, 6 \mathrm{a}, 8 \mathrm{i}, 8 \mathrm{a}$
12) Jurudemung
: $8 \mathrm{a}, 8 \mathrm{u}, 8 \mathrm{u}, 8 \mathrm{a}, 8 \mathrm{u}, 8 \mathrm{a}, 8 \mathrm{u}$
13) Wirangrong
$: 8 \mathrm{i}, 8 \mathrm{o}, 10 \mathrm{u}, 6 \mathrm{i}, 7 \mathrm{a}, 8 \mathrm{a}$
14) Balabak
15) Girisa
$: 12 \mathrm{a}, 3 \mathrm{e}, 12 \mathrm{a}, 3 \mathrm{e}, 12 \mathrm{a}, 3 \mathrm{e}$
: 8a, 8a, 8a, 8a, 8a, 8a, 8u/i/e

Masing-masing tembang tersebut di atas memiliki sejumlah cengkok (gaya lagu). Hal ini dimungkinkan karena pola pikir kebudayaan Jawa sangat memperhatikan kepribadian orang-seorang, sehingga masing-masing individu dalam masyarakat Jawa mendapatkan harga dan nilai yang terhormat, namun tidak liberal. Dhandanggula misalnya mengenal 17 cengkok. Suratno Adiyoso menggolongkan tembang macapat dan tembang tengahan sebanyak 15 buah ke dalam satu kelompok, mengutip dari penggabungan (Hardjawiraga,1989: 28). Sedangkan menjumlahkan jenis tembang macapat yang digabung dengan tembang tengahan sebanyak 15 tembang (Saputra, 1992: 47).

Sulitnya membedakan antara tembang cilik, tembang tengahan dan tembang gede bagi generasi sekarang dan selanjutnya maka penulis setuju apabila semua tembang yang ada dalam sastra Jawa digabung menjadi satu dengan nama tembang macapat yang hingga sekarang ada 15 tembang sebagaimana yang dijelaskan di atas.

\section{Tembang Macapat Sebagai Media Dakwah Islam}

Di samping perdagangan, saluran dan cara Islamisasi di Indonesia yang dilakukan para Mubaligh khususnya yang tergabung dalam Wali Songo adalah melalui cabang-cabang seni dan budaya, seperti seni pertunjukan wayang, gamelan, dan seni ukir. Para mubaligh Islam mengambil siasat menjadikan bentuk-bentuk seni dan budaya sebagai media dakwah guna memasukkan ajaran 
Islam kepada masyarakat melalui apa yang selama ini menjadi kegemarannya. Hal ini menunjukkan bahwa proses Islamisasi dilakukan dengan amat bijaksana dan berjalan dengan damai. Jika dilihat dari segi ilmu jiwa dan taktik perjuangan, maka cara dakwah lewat seni dan budaya ini merupakan strategi dakwah yang lebih mengutamakan isi daripada dakwah bentuk lahiriyah. Di samping itu cara ini ditempuh untuk menarik simpati rakyat, sehingga mereka dengan mudah menerima Islam sebagai pedoman hidupnya.

Jenis kesenian yang banyak dipergunakan sebagai media dakwah adalah melalui seni pertunjukan wayang. Sebagai pelengkap pertunjukan wayang, Wali Songo juga mengubah bentuk dan isi tembang macapat. Syair-syairnya digubah sedemikian rupa dengan muatan keagamaan, pendidikan, dan falsafah kehidupan. Sunan Giri mengubah tembang Asmaradhana, Pucung, dan Lir-Ilir; Sunan Kudus menggubah tembang Maskumambang dan Mijil; Sunan Muria menggubah tembang Sinom dan Kinanti; dan Sunan Drajat menggubah tembang Pangkur (PW. LP Ma'arif Jawa Timur, tt.). Sebagian lagu atau tembang yang digubah oleh para Wali Songo tersebut masuk dalam kelompok tembang macapat.

Sekarang ini macapat tampil di dalam perayaan hari besar dan juga keperluan lain, bahkan menjadi salah satu kegiatan lomba. Macapat yang berfungsi serba bisa dalam segala cuaca mampu menyelesaikan dengan segala suasana yang sejalan dengan kondisi pengungkapannya.

Dalam dunia dakwah, di zaman moder ini tembang macapat masih sering digunakan oleh para Dai/Mubaligh seperti Almarhum KH. Yasin dari Kediri, Almarhum KH. Maghfur Hasbullah dari Ponorogo, KH. Mudhofar Maksum dari Blitar, KH. Harun dari Kediri, KH. Ma'ruf dari Sragen, Ki Joko Goro Goro dari Demak maupun para mubaligh lain yang banyak keliling dakwah di masyarakat.

Dalam kajian ini dicontohkan beberapa bait tembang macapat yang mengandung nilai religius serta sering digunakan sebagai media dakwah para mubaligh, antara lain:

Siswa samya, wedhiya mring Gusti// bakal tuna, yentha padha lena// gyo tindakno sak dawuhe//nadyan dawuhipun//saranane angel kepati// kating-galna waler iro// sakabehing saru// tinibihno laku cidro// asyukura kabeh peparinging Gusti// jiwamu resikana (Tembang Dandanggula).

Artinya: Siswa semua, takutlah kepada Allah// Akan celaka, apabila semua terlena//Ya kerjakan perintah-Nya// Walaupun perintah-Nya// Sarananya sangat sulit// Tinggalkanlah larangan-Nya// Semua perbuatan 
tercela// Jauhkanlah dari perbuatan nista// Bersyukurlah semua pemberian Gusti// Jiwamu bersihkanlah.

Trapsilaning manembah ing Gusti// Takwa mring Hyang Manon// Rina wengi anyebut asmane// Nindakake prentahing Hyang Widhi// Ngedohi pakarti// Ambeg angkara dur. (Serat Wulang Reh Sinuwun Paku Buwana IV, Pupuh Mijil 6). Artinya: Tata cara menyembah Tuhan// Bertakwa kepada Tuhan Yang Maha Tahu// Siang malam menyebut asma-Nya// Melakukan perintah Tuhan// Menjauhi pekerti// Yang bersifat angkara murka.

Dan tentunya masih banyak lagi bait-bait tembang macapat yang memiliki nilai-nilai religius yang tinggi, pendidikan moral dan budi pekerti yang dapat digunakan sebagai media dakwah dan pendidikan kepada masyarakat luas. Sejarah mencatat para cerdik cendekiawan, Wali Songo, para juru dakwah, ahli didik masyarakat Jawa sudah sejak lama menggunakan media tembang macapat sebagai sarana pendidikan dan dakwah yang efektif. Dengan belajar dari keberhasilan dakwah yang dilakukan para mubaligh tempo dulu maupun sekarang yang salah satu materinya disampaikan melalui tembang macapat maka para pendidik maupun mubligh generasi sekarang ini juga perlu memahami makna yang tersurat maupun tersirat dalam tembang macapat sebagai media efektif dalam pendidikan dan dakwah kepada masyarakat luas dengan berbagai latar belakangnya.

\section{Simpulan}

Dari kajian pengaruh Islam dalam perkembangan budaya Jawa tembang macapat dapat disimpulkan bahwa berdasarkan beberapa pendapat tembang macapat lahir dan berkembang abad XVI pada zaman kerajaan Islam (Demak, Pajang, dan Mataram) dan para Wali Songo sebagai pengubahnya walaupun tetap dipengaruhi oleh model metrum sastra yang telah berkembang sebelumnya yaitu model kakawin dan kidung. Dari pendapat ini teranglah bahwa ajaran Islam memiliki pengaruh besar terhadap perubahan bentuk dan isi atau amanat yang terkandung dari sastra Jawa Kuno yang berbentuk kakawin, kemudian berkembang menjadi kidung pada masa Jawa Madya (Tengahan) kemudian menjadi tembang macapat. Dengan demikian ada dua pengaruh penting kedatangan Islam terhadap perkembangan tembang macapat, yaitu: yaitu pertama, pengaruh model metrum dari kakawin dan kidung berubah menjadi metrum macapat yang terdiri dari 15 metrum tembang, setiap metrum memiliki perwatakan, guru gatra, guru lagu, dan guru wilangan. Kedua, pengaruh isi. Isi kakawin dan 
kidung masih dipengaruhi unsur Hindu dan Budha sedang isi atau pesan macapat banyak diisi dengan unsur ajaran-ajaran Islam.

\section{Daftar Pustaka}

Arikunto, Suharsimi. 2000. Manajemen Penelitian. Jakarta: Rineka Cipta.

Bleicher, Josep. 1980. Comtemporary Herminiutics as Method Philosophy and Critiqu. London: Reutledge Paul.

Brandes, Jan Laurens Andries. 1901. Beschrijuing Der Javaansche, Balineesche En Sasaksche Handschriften, Part 1: Adigama-Ender.

Pemprov DKI Jakarta. 2012. Andries Brandes, JL. http://www.jakarta.go.id/, Diakses 4 Februari 2012.

Hartini. Tt. Nilai-Nilai Moral Dalam Serat Klasik Jawa Wedha-Ma Sapta. Jurusan Sastra Daerah FSSR UNS. tt. [http://www.google/searching]. Diakses Sabtu, 8 Agustus 2009.

Heekeren, H.R., van. 1975. Chronology of The Indonesian Prehistory. In: G. J. Bartstra \& W. A. Casparie (Eds.), Modern Quaternary Research in Southeast Asia 1 pp. 47-51. Rotterdam: A.A. Balkerna Publishers.

Laginem, [et al.]. 1996. Macapat Tradisional Dalam Bahasa Jawa. Jakarta: Pusat Pembinaan dan Pengembangan Bahasa.

Margono. 2000. Metode Penelitian Pendidikan. Jakarta: Rineka Cipta.

Moleong, Lexy J. 1990. Metode Penelitian Kualitatif. Bandung: Remaja Rosda Karya.

Muhadjir, Noeng. 1992. Metode Penelitian Kualitatif. Yogyakarta: Rake Sarasin.

Mulyono. 2007. Kajian Nilai Pendidikan Islam Dalam Teks Tembang Macapat (Studi Nilai Pendidikan Islam Berbasis Kultural). el-Harakah - Jurnal Budaya Islam, UIN Malang, Vol. 9, No. 2, Mei-Agustus 2007, 117-134.

Poerbatjaraka, R. Ng. 1952. Riwajat Indonesia, djilid I, "Çrivijaya, de Sanjaya en de Çailendrawamça”, B.K.I., 254-264.

Poerbatjaraka, Raden Mas Ngabei. 1952. Riwajat Indonesia. Djilid I. Djakarta: Jajasan Pembangunan. 
Pradipta, Budya. 1993/1994. Kehidupan Macapat di Propinsi Jawa Tengah, Jakarta: Proyek Penelitian dan Pengkajian Kebudayaan Nusantara Depdikbud.

Purna, I Made. dkk. 1996. Macapat dan Gotong Royong, Macapat dan Gotong Royong, Jakarta: Direktorat Sejarah dan Nilai Tradisional Direktorat Jenderal Kebudayaan Departemen Pendidikan dan Kebudayaan.

Rochyatmo, Amir. Tt. Tembang Macapat yang Tersurat dan Tersirat. Jakarta.

Saputra, Karseno. 1992. Pengantar Sekar Macapat. Universitas Indonesia.

Tim Penyusun Buku Agama LP Maarif NU. tt. Pendidikan Aswaja Ë Ke-NU. an Untuk MA/SMU/SMK Kelas 1. Surabaya: PW LP Maarif NU Jawa Timur.

Tim Wacana Nusantara. 2009. Tembang Macapat. 19 Maret 2009. http://www. wacananusantara.org/ Diakses Sabtu, 8 Agustus 2009.

Wibisono, Singgih. 2009. Selisik Budaya Jawa Menuju Kebangkitan, Superkoran. http://www.apakabar.ws/ [Online] Sabtu, 8 Agustus 2009.

Zoetmulder, PJ. 1982. Melestraikan Pancasila dengan Lagu Tembang Jawa. Jakarta: BP7 Pusat. 